\title{
Novel mechanism of mitral regurgitation after lung transplantation in a patient with scleroderma and pulmonary hypertension
}

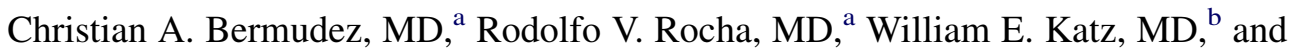 \\ Yoshiya Toyoda, MD, PhD, ${ }^{\text {a }}$ Pittsburgh, $\mathrm{Pa}$
}

Valvular complications after lung transplantation (LTx) are rare. Mitral regurgitation (MR) after LTx has been associated only with acute endocarditis in immunosuppressed patients. ${ }^{1,2}$ We report an unusual case of severe MR diagnosed in the late postoperative course of LTx, in the absence of infection.

\section{CLINICAL SUMMARY}

A 43-year-old woman with a history of scleroderma complicated by advanced respiratory failure secondary to pulmonary fibrosis and hypertension was considered for LTx. Pulmonary artery pressures of $81 \mathrm{~mm} \mathrm{Hg}$ (systolic) and $38 \mathrm{~mm} \mathrm{Hg}$ (diastolic) with a transpulmonary gradient of $38 \mathrm{~mm} \mathrm{Hg}$ were associated with severe tricuspid regurgitation, severe right ventricular dilatation, and moderate dysfunction. She underwent a successful double LTX and a tricuspid valve annuloplasty using the De Vega technique. Surgery was performed on cardiopulmonary bypass with an allograft ischemic time of 405 minutes. Intraoperative transesophageal echocardiography showed preserved left ventricular function with moderate right ventricular dilatation and no evidence of tricuspid regurgitation or MR.

The patient experienced primary graft dysfunction early postoperatively and required venoarterial extracorporeal membrane oxygenator (ECMO) support for 3 days, using central cannulation. ECMO weaning was considered after recovery of lung function with a $\mathrm{PAO}_{2}$ of $76 \mathrm{~mm} \mathrm{Hg}$ on $40 \% \mathrm{FIO}_{2}$ and significant radiologic improvement.

After ECMO weaning, several extubation attempts were unsuccessful, despite adequate allograft function. A biopsy, 15 days after LTx, showed no acute cellular rejection or diffuse alveolar damage. The patient had 2 episodes, on days 9 and 22 after transplant, of acute desaturation with a mod-

\footnotetext{
From the Department of Cardiothoracic Surgery ${ }^{a}$ and University of Pittsburgh Medical Center Cardiovascular Institute, ${ }^{\text {b }}$ University of Pittsburgh Medical Center, Pittsburgh, $\mathrm{Pa}$.

Disclosures: Authors have nothing to disclose with regard to commercial support.

Received for publication June 28, 2010; accepted for publication Sept 22, 2010; available ahead of print Nov 15, 2010.

Address for reprints: Christian A. Bermudez, MD, Assistant Professor, University of Pittsburgh Medical Center-Presbyterian University Hospital, 200 Lothrop St, Suite C900, Pittsburgh, PA 15213 (E-mail: bermudezc@upmc.edu).

J Thorac Cardiovasc Surg 2011;141:e1-3

$0022-5223 / \$ 36.00$

Copyright (C) 2011 by The American Association for Thoracic Surgery

doi:10.1016/j.jtcvs.2010.09.027
}

erate degree of pulmonary congestion, which were initially assumed to be related to primary graft dysfunction. Manual ventilation and sedation allowed respiratory stabilization to baseline. A third episode occurred 42 days after transplant, with severe desaturation, and was associated with significant pulmonary edema with frothy serosanguinous fluid. The patient was hypoxemic, with a $\mathrm{PAO}_{2}$ of $35 \mathrm{~mm} \mathrm{Hg}$ and an elevated peak inspiratory pressure of $37 \mathrm{~mm} \mathrm{Hg}$, requiring $100 \% \mathrm{FIO}_{2}$ temporarily. A transthoracic echocardiogram revealed severe MR with centrally oriented regurgitation, which had not been present in prior echocardiographic examinations, with normal valvular anatomy but absence of coaptation between the anterior and the posterior leaflets. No signs of endocarditis were found.

On the basis of the clinical course, we decided to perform a mitral valve repair 44 days after LTx. Via a right anteroaxillary thoracotomy approach (previously used for the transplant), on cardiopulmonary bypass, under ventricular fibrillatory arrest, and through the left atrium, a 26-mm Cosgrove-Edwards mitral band (Edwards Lifesciences, Irvine, Calif) was placed, correcting the MR. After an uneventful surgery, the patient recovered with no complications and was removed from mechanical ventilation 5 days later.

\section{DISCUSSION}

This was a rare case of severe noninfectious MR complicating the postoperative course of a double LTx. To our knowledge, no similar case has been reported. The mechanism underlying MR in this patient may be related to subacute anatomic changes of the right and left ventricular chambers with subsequent changes in the mitral annulus. Another case of subacute progression of MR, perhaps due to a similar mechanism, was previously seen at the University of Pittsburgh Medical Center after double LTx for primary pulmonary hypertension and was treated conservatively.

To corroborate this theory, we examined the left ventricular and mitral valve size before and after LTx in our patient. The reduction in systolic pulmonary pressure, from 82 to $34 \mathrm{~mm} \mathrm{Hg}$, that occurred after LTx was associated with a reduction in the size of the right ventricle, producing inverse changes in the left ventricle and mitral annulus. The mitral annular dimension, measured in diastole, increased $0.9 \mathrm{~cm}(30 \%$; from 2.17 to $3.08 \mathrm{~cm})$ (Figure 1). The diameter of the left ventricle in diastole increased 


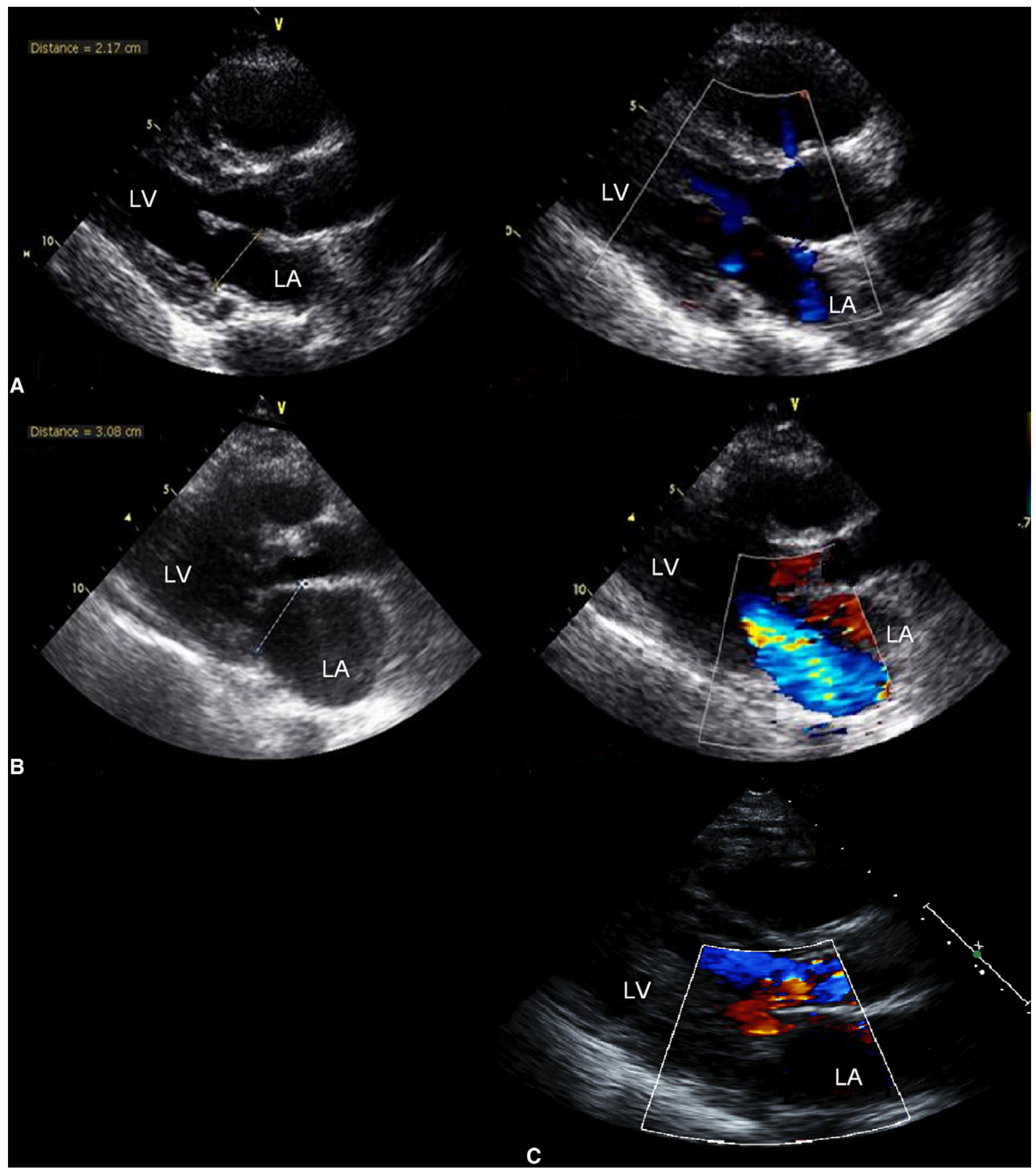

FIGURE 1. A, Pretransplant transthoracic echocardiogram with absence of MR on color Doppler. B, Posttransplant transthoracic echocardiogram with dilatation of the mitral annulus and the presence of severe MR on color Doppler. C, Post-mitral valve repair transthoracic echocardiogram with absence of MR on color Doppler. (Color Doppler is shown on the right side of each panel.) $L A$, Left atrium; $L V$, left ventricle.

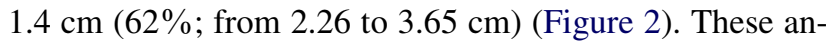
atomic changes are consistent with the pathophysiologic mechanism of MR - a clear lack of coaptation between the anterior and posterior leaflets without leaflet prolapse or chordal rupture. The implantation of a $26-\mathrm{mm}$ band easily corrected the regurgitation, supporting this theory. No signs of the mitral chordal or leaflet thickening, seen previously in a patient with scleroderma, ${ }^{3}$ or the early left 


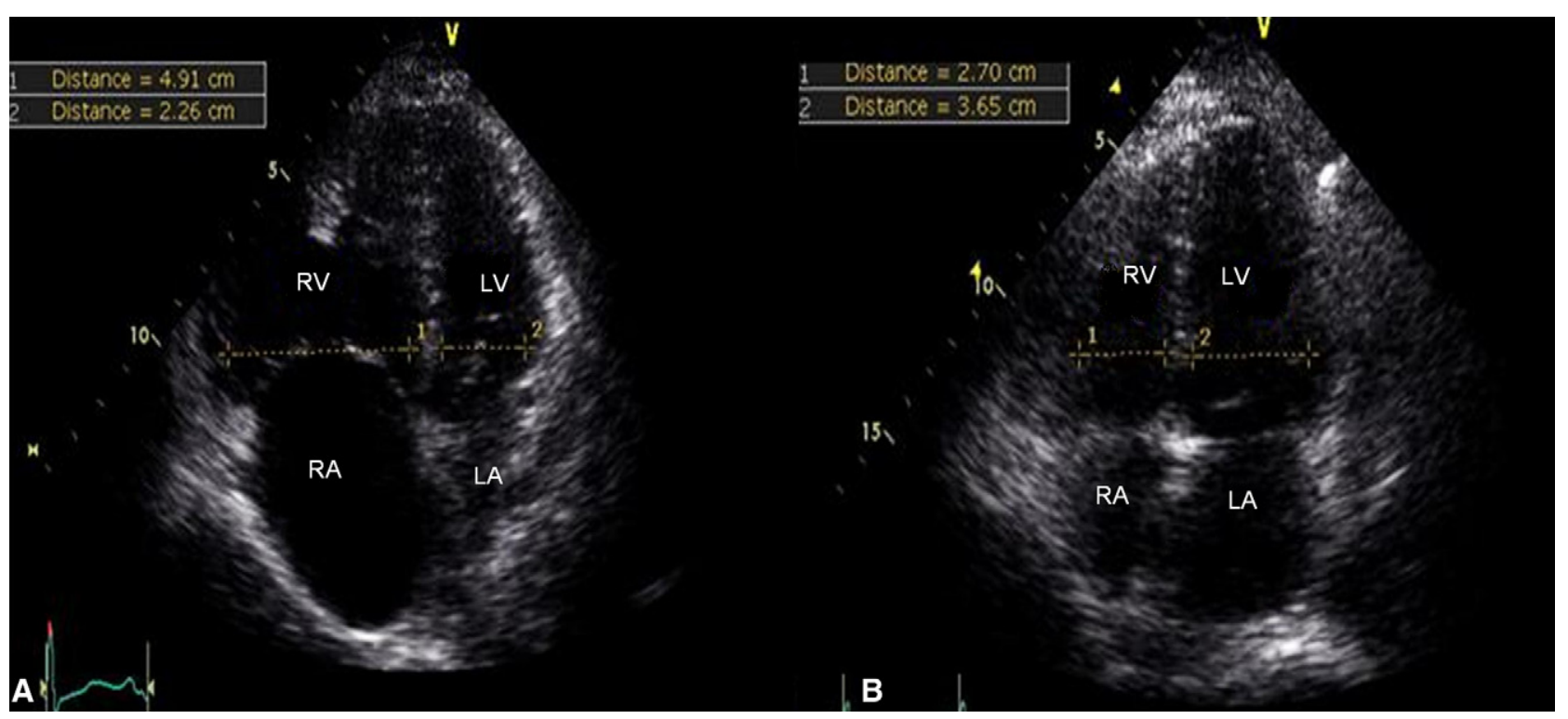

FIGURE 2. Transthoracic echocardiogram pretransplant (A) and posttransplant (B), showing changes in right and left ventricular diameters. $L A$, Left atrium; $L V$, left ventricle; $R A$, right atrium; $R V$, right ventricle.

ventricular dysfunction seen in patients undergoing LTx for pulmonary hypertension ${ }^{4}$ were associated with the mechanism of regurgitation in this case. The influence of the tricuspid annuloplasty remains unclear, requiring further analysis.

\section{CONCLUSIONS}

We report this unusual case because it demonstrates a rare mechanism of MR after LTx requiring surgical repair. Close observation of left ventricular and mitral annular anatomy is necessary after LTx in patients with severe pulmonary hypertension. Inverse remodeling of the left-sided structures could be associated with clinically relevant, new-onset MR.

\section{References}

1. Saxena P, Clarke B, Dunning J. Aspergillus endocarditis of the mitral valve in a lung-transplant patient. Tex Heart Inst J. 2007;34:95-7.

2. Scherer M, Fieguth HG, Aybek T, et al. Disseminated Aspergillus fumigatus infection with consecutive mitral valve endocarditis in a lung transplant recipient. J Heart Lung Transplant. 2005;24:2297-300.

3. Khouzam R, D'Cruz I, Arroyo M. Systematic scleroderma with moderate to severe mitral regurgitation: unusual three-dimensional echocardiographic features. Can J Cardiol. 2008;24:152

4. Bîrsan T, Kranz A, Mares P, et al. Transient left ventricular failure following bilateral lung transplantation for pulmonary hypertension. J Heart Lung Transplant. 1999;18:304-9.

\section{Third-time lung transplantation in a patient with cystic fibrosis}

Nakul Vakil, MD, David P. Mason, MD, James J. Yun, MD, PhD, Sudish C. Murthy, MD, PhD, Marie M. Budev, DO, and Gosta B. Pettersson, MD, PhD, Cleveland, Ohio

From the Department of Thoracic and Cardiovascular Surgery, Heart and Vascular Institute, Cleveland Clinic, Cleveland, Ohio.

Disclosures: Authors have nothing to disclose with regard to commercial support.

Received for publication Aug 2, 2010; accepted for publication Sept 2, 2010; available ahead of print Nov 19, 2010.

Address for reprints: David P. Mason, MD, Department of Thoracic and Cardiovascular Surgery, Heart and Vascular Institute, Cleveland Clinic, 9500 Euclid Avenue/Desk J4-1, Cleveland, OH 44195 (E-mail: masond2@ccf.org).

J Thorac Cardiovasc Surg 2011;141:e3-5

$0022-5223 / \$ 36.00$

Copyright (c) 2011 by The American Association for Thoracic Surgery doi:10.1016/j.jtcvs.2010.09.028
Respiratory failure is the leading cause of death in patients with cystic fibrosis (CF), and lung transplantation (LTx) is the only treatment option for patients with end-stage disease. Unfortunately, the long-term success of LTx is limited by the development of bronchiolitis obliterans syndrome (BOS), and retransplantation (re-LTx) for these patients is infrequent and controversial. ${ }^{1-4}$ Concerns include (1) the technical difficulty of re-LTx; (2) immunologic barriers imparting worse survival in patients whose first grafts 